\title{
Narrativa, identidade e feminilidades periféricas
}

DOI: http://dx.doi.org/10.21165/el.v49i3.2576

Fábio Fernando Lima'

\section{Resumo}

Este artigo apresenta uma análise e descrição de questões atinentes à construção das identidades sociais e suas intersecções com relações de poder e hegemonia em entrevistas colhidas com mulheres pobres, negras, com baixa escolaridade e residentes em áreas periféricas. Para a operacionalização da análise, propomos estabelecer pontos de contato teórico-metodológicos entre a Análise Crítica do Discurso e a Análise da Narrativa. Os resultados tanto ressaltaram que a "avaliação" pode se constituir no principal viés a alinhavar ambas as vertentes teóricas quanto apontaram para um profundo imbricamento entre os atravessamentos "gênero" e "classe social", ratificando a necessidade teórica de se considerar o sujeito social interseccionado por tais atravessamentos, a partir dos quais constroem suas identidades e atribuem sentidos do mundo ao seu redor.

Palavras-chave: Análise Crítica do Discurso; Análise da Narrativa; identidades; avaliação; hegemonia; feminilidades.

1 Pontifícia Universidade Católica do Rio de Janeiro (PUC-Rio), Rio de Janeiro, Rio de Janeiro, Brasil; fabiofernandolima@uol.com.br; http://orcid.org/0000-0002-1632-9463 


\title{
Narrative, identity and peripheral femininity
}

\begin{abstract}
This article presents an analysis and description of issues related to the construction of social identities and their intersections with power relations and hegemony in interviews with poor, black, low-educated women living in peripheral areas. For the operationalization of the analysis, we propose to establish theoretical-methodological contact points between Critical Discourse Analysis and Narrative Analysis. The results both emphasized that the "evaluation" may constitute the main bias to align both theoretical aspects and pointed to a deep intertwining between the "gender" and "social class" intersections, ratifying the theoretical need to consider the social subject intersected by such crossings, from which they construct their identities and assign meanings of the world around them.
\end{abstract}

Keywords: Critical Discourse Analysis; Narrative Analysis; identities; evaluation; hegemony; femininities.

\section{Introdução}

A proposta de se estabelecer um diálogo teórico e metodológico entre a Análise da Narrativa e a Análise Crítica do Discurso, tarefa que elegemos como central neste artigo, segue pistas importantes deixadas na constituição teórica de ambas as vertentes, as quais tomamos por embasamento. Segundo Bastos e Biar (2015), a Análise da Narrativa inscreve-se no contexto do compromisso social e político que ecoa na proposta programática para a Linguística Aplicada contemporânea (cf. MOITA LOPES, 2001, 2006, dentre outros), debruçada sobre a linguagem e sua relação com a vida social.

Ao defender que o significado é construído na alteridade, "co-construído pela ação em conjunto de participantes discursivos em práticas discursivas, situadas na história, na cultura e na instituição" - ideia central do socioconstrucionismo propriamente dito - o que "ressalta as contingências culturais, históricas e institucionais que atuam sobre a ação discursiva", Moita Lopes (2001, p. 58) assume explicitamente a posição estabelecida, no âmbito da ACD, por Fairclough (1992, p. 3), especificamente aquela responsável por defender que "os discursos não somente refletem ou representam as entidades e relações sociais, eles as constroem ou as constituem". É nesse sentido que o autor afirma que a concepção de discurso que tem orientado seu trabalho "enfatiza sua natureza social", "à luz de vários pesquisadores como Fairclough" (MOITA LOPES, 2001, p. 57).

Admitindo que o discurso é constitutivo da vida social, a compreensão do discurso como co-construção social implica apreendê-lo enquanto ação através da qual os participantes discursivos se constroem, constroem os outros e, portanto, constituem o mundo social. Estudar o discurso nessa perspectiva é examinar seus efeitos sociais nas 
práticas discursivas em que agem os interlocutores, o que envolve entender como cada interactante constrói a sua identidade social e/ou a dos seus interlocutores².

Para Bastos e Biar (2015, p. 102), o projeto construcionista "conceberia a ideia de validade de acordo com um compromisso ético: as interpretações válidas são aquelas que se comprometem com a desconstrução de práticas sociais injustas e com a transformação destas (a partir de uma visão aplicada de ciência)".

Nesse contexto, as pesquisas nessa área fariam parte de um projeto epistemológico interdisciplinar, e a Análise de Narrativa configurar-se-ia como uma proposta útil a esse projeto, na medida em que:

(i) promove diálogo entre múltiplas áreas do saber; (ii) se debruça sobre a fala dos mais diversos atores sociais, nos mais diversos contextos; (iii) reverbera entendimento do discurso narrativo como prática social constitutiva da realidade; (iv) nega a possibilidade de se delinear as identidades estereotipadamente, como instituições pré-formadas, atentando para os modos como os atores sociais se constroem para fins locais de performação [...] e (v) avança no entendimento sobre os modos como as práticas narrativas orientam, nos níveis situados de interação, os processos de resistência e reformulação identitária. (BASTOS; BIAR, 2015, p. 102-103).

De acordo com as autoras, essa descrição, que se dá em nível microanalítico, sobre as relações observáveis entre narradores e ouvintes, pode gerar extrapolações sóciopolíticas sobre, por exemplo, como se constroem, interacionalmente, as relações de poder entre os participantes.

Ora, a ACD apresenta-se, justamente, como um campo de investigação fundamentalmente interessado em propor uma teoria e um método para descrever, interpretar e explicar as relações estruturais, transparentes ou veladas, de poder e controle manifestos na linguagem (cf. WODAK, 2004). Assume-se, assim, como ponto central, a análise das maneiras pelas quais "o discurso contribui para a reprodução da desigualdade e da injustiça social, determinando quem tem acesso a estruturas discursivas e de comunicação aceitáveis e legitimadas pela sociedade" (VAN DIJK,1994, p. 4-5).

2 Baseados no modelo elaborado por Fairclough (2001) concebemos, por "discurso", por um lado, de forma semelhante à Pragmática e às perspectivas interacionistas, como "um modo de ação, uma forma em que as pessoas podem agir sobre o mundo e especialmente sobre os outros". Mas, a essa definição, ainda de acordo com o autor, o discurso é também um modo de "representação", o que "implica uma relação dialética entre o discurso e a estrutura social, existindo mais geralmente tal relação entre a prática social e a estrutura social: a última é tanto uma condição como efeito da primeira" (FAIRCLOUGH, 2001, p. 91). 
É partindo desses pressupostos que buscamos estabelecer uma associação teórica e metodológica entre a Análise da Narrativa e a $\mathrm{ACD}^{3}$, e aplicar o modelo daí decorrente à abordagem de entrevistas colhidas em Centros de Referência de Assistência Social (CRAS) com mulheres negras, pobres, em condições precárias de inserção no mercado de trabalho, com baixa escolaridade e residentes em áreas periféricas, atendidas por programas socioassistenciais. Mediante a análise dessas entrevistas e das narrativas que nelas emergiram, procuramos estabelecer articulações com o contexto macro-contextual ou sócio-histórico, observando, por exemplo, as maneiras pelas quais os estereótipos são aceitos ou rejeitados, quais recorrências ou resistências estão presentes, ou como as identidades localmente instituídas relacionam-se com discursos especializados ou de senso comum que circulam na sociedade.

A abordagem das questões "macro-sociais" ou "sócio históricas" será alcançada mediante extrapolações derivadas de microanálises das interações em questão.

\section{A Análise Crítica do Discurso}

A proposta teórica desenvolvida por Fairclough (1992, 2001, 2003, dentre outros) para a ACD apresenta-se sob a forma de um modelo de análise tridimensional, caracterizado por apontar, para cada evento discursivo, três dimensões: uma dimensão do evento discursivo enquanto texto falado ou escrito, uma instância de prática discursiva, envolvendo a produção e a interpretação do texto e, por fim, o aspecto de prática social, envolvendo relações de ideologia e hegemonia4.

Ao conceber o discurso enquanto prática social contextualizada em uma estrutura social ampla, Fairclough $(1992,2001,2003)$ evoca uma perspectiva funcionalista da linguagem, na medida em que postula que a língua possui funções externas ao sistema e que essas funções são as responsáveis pela organização interna do sistema linguístico. Dessa maneira, no que tange à orientação linguística de sua teoria - o discurso enquanto texto - o autor mobiliza a Linguística Sistêmico-Funcional de Halliday (1985).

3 Nem de longe pretendemos dizer que "narrativa" também não seja "discurso". Apenas estamos chamando a atenção para a proposta de associação entre duas tradições teóricas distintas - a Análise da Narrativa e a ACD.

4 Entendemos, por "ideologias" - de mono análogo ao preconizado por Fairclough (2001, p. 117) -, como "significações/construções da realidade (o mundo físico, as relações sociais, as identidades sociais) que são construídas em várias dimensões das formas/sentidos das práticas discursivas e que contribuem para a produção ou a transformação das relações de dominação". Quando se tornam naturalizadas e atingem o status de "senso comum", as ideologias embutidas nas práticas discursivas são muito eficazes para a manutenção de relações de dominação. Também seguindo o autor, concebemos, por "hegemonia" "o domínio exercido pelo poder de um grupo" - e esse grupo é o grupo dominante - "sobre os demais, baseado mais no consenso que no uso da força" (FAIRCLOUGH, op. cit., p. 43). 
No modelo para a ACD apresentado em 2003, Fairclough apresenta um conjunto articulado de três significados - acionais, identificacionais e representacionais. Para este trabalho, em particular, importa a constituição dos significados acionais, que focalizam o texto como modo de (inter)ação em eventos sociais, com a ação legitimando/questionando relações sociais, e os significados identificacionais, atinentes à construção e à negociação de identidades no discurso. Os significados identificacionais e acionais estão associados à metafunção interpessoal de Halliday, e sua abordagem permite ao analista observar as maneiras pelas quais o enunciador, inserido em um determinado contexto sociocognitivo, tanto atribui determinadas identidades sociais aos atores designados em seu texto inclusive a ele mesmo, no caso das narrativas de história de vida - quanto expressa seus posicionamentos e julgamentos. É por meio desses significados que são instanciadas as relações pessoais e sociais dos participantes dos eventos discursivos, tanto no aspecto de sua configuração identitária como da sua relação com os outros atores sociais envolvidos no processo.

Nesse sentido, faz-se importante acrescentarmos que os estudos englobados pela ACD se valem das contribuições advindas de outros estudiosos que têm trabalhado, de perto, com a proposta de Halliday, os quais não apenas aplicaram essa teoria, mas também a complementaram. Para a pesquisa que aqui delineamos, levaremos em conta a proposta de análise apresentada por Martin e White (2005), denominada "Teoria da Avaliatividade". Essa proposta se caracteriza por sintetizar os estudos mencionados e propor uma categorização ainda mais abrangente dos mecanismos linguísticos acionados para o estabelecimento das relações interpessoais.

Partindo das concepções apresentadas por Fairclough no decorrer de todas as atualizações de seu modelo, Martin e White (2005) se voltam para a constituição de categorias sócio-semióticas relacionadas à construção da intimidade, distância, envolvimento, identidade e autoridade discursivas, realizadas, linguisticamente, por meio de recursos avaliativos. Segundo os autores, a atitude, o engajamento e a gradação podem ser concebidos como fenômenos linguísticos que atualizam posicionamentos intersubjetivos dos atores sociais em interação.

De acordo com esse ponto de vista, a atitude abrange significados graduáveis por meio dos quais o falante/escritor avalia entidades, estados de coisas e acontecimentos negativa ou positivamente. É subdividida em afeto (reações afetivas diante de uma situação ou comportamento específico), julgamento (avaliações acerca da capacidade, normalidade, tenacidade, propriedade e veracidade dos comportamentos ou atitudes humanas e/ou institucionais) e apreciação (avaliações de caráter estético ou valor social acerca de elementos concretos da realidade, incidindo sobre fenômenos semióticos ou naturais, de acordo com os valores de um determinado campo. Nesse sentido envolve critérios e parâmetros, diferentemente das regras, leis e regulamentos que governam os julgamentos). 
A gradação está relacionada ao modo pelo qual os falantes/escritores maximizam ou minimizam a força de suas asserções. O engajamento, por fım, constitui-se no componente por meio do qual o autor se posiciona em relação a seu enunciado e aos enunciados potenciais de outros atores sociais envolvidos na interação. Por meio dessa categoria, busca-se descrever em que medida enunciadores avaliam as afirmações anteriores, qual é o peso dessas afirmações em suas formulações e de que modo eles se engajam em relação a tais enunciados (em oposição, concordância, etc.).

\section{Narrativa, ACD e a questão da construção das identidades}

As primeiras pesquisas sobre narrativa foram elaboradas por Labov e Waletzky (1968) e Labov (1972), assentadas em uma concepção de narrativa enquanto um método de se recapitular experiências passadas. Nas palavras de Labov (1972, p. 37), "a narrativa será considerada [...] uma técnica para construir unidades narrativas que correspondem à sequência temporal daquela experiência".

No contexto da proposta canônica de narrativas bem formadas apresentada por Labov (1972), um item é de extrema importância para este trabalho em particular: a "avaliação". De acordo com o autor, a "avaliação" é o momento em que o narrador explicita sua postura em relação à narrativa, evidenciando a razão de ser da narrativa. Pode emergir sob a forma de uma avaliação externa, se o narrador optar por suspender o fluxo narrativo para observar o seu ponto, apresentando-o sob forma de um parêntese, ou ainda sob forma de uma avaliação encaixada, se o narrador, por meio de recursos expressivos, sem interrupções no fluxo de eventos narrados, inserir dramaticidade ao relato, indiciando o sentido como os acontecimentos devem ser entendidos.

Considerando-se os objetivos que norteiam este trabalho, utilizaremos esse aspecto do modelo laboviano, mas será especialmente útil a proposta dita "não-canônica" apresentada por Linde (1993), voltada para análise de narrativas de histórias de vida e experiências pessoais coletadas em entrevistas - de modo análogo ao material a ser analisado neste artigo.

De uma maneira bastante geral, podemos dizer que Linde (1993) busca demonstrar de que maneira as estruturas narrativas atuam na construção das identidades. De acordo com a autora, ao elaborar suas histórias de vida, os enunciadores buscam apresentarse e marcar sua existência a partir de critérios de propriedade e aceitação cultural, os quais estão estabelecidos socialmente: os fatos são organizados em sintonia com as crenças que circulam na sociedade. Nesse contexto, as identidades sociais emergem nas histórias de vida porque, a partir delas, os sujeitos constroem os sentidos de adesão que os enunciadores reivindicam para si mesmos. 
Em um âmbito maior, conforme afirmado anteriormente, coloca-se a pertinência da análise de questões atinentes à construção identitária e interação social na Análise da Narrativa, entendida contemporaneamente como central em estudos como os de Mishler (2002), Riessman (2008), Bastos (2005), Bastos e Biar (2015), dentre outros. Nesse sentido, propomos agregar a esses estudos o instrumental de análise que trata da constituição dos significados "identificacional" e "acional", associados à "metafunção interpessoal" na proposta de Fairclough (2003) e atrelados à construção e à negociação de identidades no discurso. Conforme mencionamos na seção anterior, essas categorias permitem observar as maneiras pelas quais o enunciador tanto atribui determinadas identidades sociais aos atores designados em seu texto quanto expressa seus posicionamentos e julgamentos, instanciando relações pessoais e sociais dos participantes dos eventos discursivos, tanto no aspecto de sua configuração identitária quanto da sua relação com os outros atores sociais envolvidos no processo.

Segundo Fairclough (2001), a função de identidade é preponderante porque os modos de construção e categorização de identidades em uma dada sociedade dizem respeito a seu funcionamento no que concerne às relações de poder, à reprodução e à mudança social, à medida que legitima/questiona relações sociais. E, conforme bem lembra Bastos (2005), ao se referir à Análise da Narrativa, as escolhas que fazemos ao nos introduzirmos como personagens em certos cenários, em meio a outros personagens e ações, se dão em função do modo como nos posicionamos em relação a esses elementos e nos afiliamos a certas categorias sociais, mesmo que contingencialmente, sendo parte de um processo de apresentação e interpretação de pelo menos algumas dimensões de quem somos: "ao contar estórias, situamos os outros e a nós mesmos numa rede de relações sociais, crenças, valores, ou seja, ao contar estórias, estamos construindo identidades" (BASTOS, 2005, p. 81).

A partir da análise das narrativas, é possível elaborar articulações com o contexto macro-contextual ou sócio-histórico, perguntando-se, por exemplo, como estereótipos são aceitos ou rejeitados, e como as identidades localmente instituídas relacionam-se com discursos especializados ou de senso-comum que circulam na sociedade. Interessa observar aspectos como discurso reportado, avaliação e, ainda, como os tópicos são introduzidos, que recorrências ou resistências estão presentes e como funcionam em relação ao que está sendo dito (no que tange a ilustrações, explicações, argumentos).

Considerando a importância da "avaliação" para o modelo laboviano e para os modelos não-canônicos em geral, podemos afirmar que a associação com a análise dos recursos avaliativos - e por conseguinte, à função identificacional de Fairclough (2003) certamente poderá se traduzir em um ganho para o instrumental teórico-analítico da Análise da Narrativa. 
Para Bastos (2005), é por meio da avaliação que o enunciador encontra espaço para comentar aspectos do que foi narrado, deixando entrever suas crenças, valores, afiliações, posicionamentos na hierarquia social e qualificações. Por isso mesmo, Biar (2012, p. 177) afirma que a avaliação se configura, então, "como o aspecto mais fundamental para a construção de identidade".

Para Linde (1997), a avaliação é justamente o momento da narrativa em que emergem pistas sobre as maneiras pelas quais as narrativas devem ser compreendidas e quais valores morais estão atribuídos aos personagens e eventos narrados. Nesse sentido, de uma maneira mais aberta que aquela observada no modelo canônico de Labov (1972) e Labov e Waletzky (1968), a autora entende por "avaliação" "qualquer instanciação produzida pelo falante que tenha sentido social ou indique o valor de uma pessoa, coisa, evento ou relacionamento" (LINDE, 1997, p. 152). Amplia-se, portanto, a associação entre avaliação e dimensão moral da narrativa.

Na verdade, nesse processo de ampliação do modelo laboviano, Linde (1997) propõe a existência de uma dimensão avaliativa que faz "referência às normas sociais". De acordo com a autora, trata-se de um aspecto estruturante das narrativas, relacionado ao fato de elas conterem, inevitavelmente, comentários morais, avaliações sobre quais comportamentos são adequados ou não e julgamentos normativos sobre os atores sociais das histórias narradas. Para Linde (1997, p. 153), "uma avaliação desse tipo compõe o coração da narrativa; a narrativa oral visa muito mais a alcançar um acordo sobre significados morais em diversas ações do que um simples reportar dessas mesmas ações".

Profundamente semelhante, portanto, ao conceito de avaliatividade assumido por Martin e White (2005), é este conceito de "avaliação narrativa" que adotaremos no presente trabalho.

\section{Metodologia}

A presente pesquisa, de inspiração etnográfica, teve início com a observação participante do pesquisador nas reuniões do grupo de mulheres atendidas pelo Serviço de Convivência e Fortalecimento de Vínculos (SCFV) de um pequeno município do noroeste paulista. Cumpre destacar que o SCFV é um serviço da Proteção Social Básica do Sistema Único de Assistência Social (SUAS) que é ofertado de forma complementar ao trabalho social com famílias, realizado por meio do Serviço de Proteção e Atendimento Integral às Famílias (PAIF) e do Serviço de Proteção e Atendimento Especializado às Famílias e Indivíduos (PAEFI). 
Ofertado geralmente nos Centros de Referência da Assistência Social (CRAS) (ou nos Centros de Convivência), o SCFV realiza atendimentos em grupo, subdivididos em geral por faixas etárias. Para cada grupo, são desenvolvidas atividades artísticas, culturais, de lazer e esportivas, dentre outras, de acordo com a idade dos usuários. Caracteriza-se como uma forma de intervenção social planejada que cria situações desafiadoras, estimula e orienta os usuários na construção e reconstrução de suas histórias e vivências individuais, coletivas e familiares, objetivando fortalecer as relações familiares e comunitárias, além de promover a integração e a troca de experiências entre os participantes, valorizando o sentido de vida coletiva.

Considerando que, dentre o público-alvo, esse serviço é voltado também para mulheres inscritas no Cadastro Único, beneficiárias de programas socioassistenciais, com o objetivo de fortalecê-las e protegê-las, procedemos posteriormente à entrevista etnográfica com mulheres atendidas pelo SCFV, sendo essas entrevistas o material a ser analisado neste artigo.

Conforme afirma Resende (2014), embora não haja referências explícitas na ACD acerca da relação com a Etnografia, a alternativa teórica transdisciplinar assumida por essa vertente de estudos do discurso permite acrescentarmos ao leque de possibilidades essa área de conhecimento. Como observamos em Magalhães (2006, p. 62):

Defendemos a etnografia como uma metodologia adequada para o estudo da prática social. Na perspectiva que adotamos, o discurso (incluindo aspectos semióticos ligados à imagem) é uma dimensão da prática social [...]. Isso significa que os textos - a materialidade linguística e semiótica das práticas sociais precisam ser contextualizadas nas práticas, o que exige um trabalho de campo.

Ao se associar, ainda ao campo teórico da Análise da Narrativa, o presente estudo insere-se numa abordagem sociointeracional do discurso e esta pesquisa assume uma natureza qualitativa e interpretativista. Segundo Denzin e Lincoln (2006, p. 17), a pesquisa qualitativa interpretativista constitui-se em uma atividade situada, que busca "entender, ou interpretar, os fenômenos em termos dos significados que as pessoas a eles conferem". Isto é, visa a compreender o mundo social a partir da perspectiva dos próprios atores sociais, com base na forma como significam a si, aos outros e ao mundo. Portanto, ao privilegiar a multiplicidade de valores e significados naturalmente arraigados à investigação e ao objeto analítico, o pesquisador passa a atuar como intérprete dos processos de construção simbólica, que não podem ser medidos em termos quantitativos (DEZIN; LINCOLN, 2006).

A entrevista qualitativa constitui-se em importante ferramenta da pesquisa interpretativista, principalmente no que tange ao estudo da narrativa, posto que "a análise de como e o que as pessoas narram em entrevistas de pesquisa remete a estruturas 
socioculturais mais amplas, ao universo social no qual transitam os interactantes" (BASTOS; SANTOS, 2013). De forma análoga, Mishler (1986) defende a entrevista como o método básico de pesquisa nas ciências sociais, sendo uma das ferramentas mais utilizadas em pesquisas nessa área. Além disso, conforme aponta o autor, as entrevistas propiciam a ocorrência de histórias, o que corrobora a decisão por essa ferramenta.

\section{Análise dos dados}

Por adotarmos, como material para a análise desta pesquisa, narrativas de histórias de vida advindas de entrevistas realizadas com mulheres negras, pobres, em condições precárias de inserção no mercado de trabalho, com baixa escolaridade e residentes em áreas periféricas, atendidas por programas socioassistenciais, temos que tratar, inevitavelmente, de atravessamentos que envolvem questões de gênero e classe social.

Cumpre acrescentarmos que estudos contemporâneos, tais como os de Freitas (2002, p. 30), têm diferenciado "sexualidade" (dimensão biológica do ser humano) de "gênero" (construto social), sustentando que "os comportamentos, sentimentos, desejos e emoções, vistos como parte de uma essência masculina ou feminina, são produtos de um determinado contexto histórico e/ou geográfico". Dessa forma, "gênero" se relaciona "às disposições morais socialmente atribuídas em contextos culturais específicos, não redutíveis à base biológica fornecida pelo sexo" (p. 31).

De uma maneira mais particular, o gênero apresenta a propriedade de permear as demais categorizações de identidade social do sujeito. De acordo com Freitas (2002, p. 33), o gênero

[...] significa uma categoria social de apreensão do mundo real e, assim como tempo e espaço, funciona como um princípio classificatório capaz de conferir significado ao sensível. Assim sendo, trespassa outros níveis da identidade: etnia, classe, religião, faixa etária etc.; desta feita, as propostas de investigação científica que giram em torno do gênero representam um desafio, por proporem uma incursão nos interstícios da masculinidade com outras variáveis socioculturais.

Nesse contexto, as narrativas relacionadas às trajetórias de vida - tais quais propomos investigar neste artigo - também podem ser entendidas como elaborações produtoras de gêneros, à medida que atualizam o sistema de gênero vigente na sociedade, articulando, certamente, estrutura e prática (ou estrutura e história, global e local, micro e macro).

Cumpre acrescentarmos que qualquer discussão sobre a questão de gênero envolve, invariavelmente, o fato de o masculino estar mais imbuído do valor social positivo, havendo uma espécie de hegemonia em torno dos seus atributos. Conforme aponta Freitas (2002, p. 38), essa "masculinidade hegemônica" 
[...] aponta para valores e conjuntos de significados que ordenam a apreensão do mundo segundo uma lógica de divisão e distribuição desigual de poder entre os gêneros. A masculinidade hegemônica subentende outras masculinidades submetidas a ela numa relação de subordinação, sendo esta assimetria consensualmente vivenciada pelos sujeitos sociais, onde os dominados (estas outras maneiras de ser masculino e todos os 'femininos') participam de sua própria dominação, na medida em que defendem (verbal e comportamentalmente) a legitimidade de apenas uma masculinidade. Assim sendo, esta masculinidade hegemônica reproduz para o interior da 'masculinidade' (conceito generalizante) as relações hierárquicas de dominação que estruturam a ideia de gênero na interação entre masculinidade/s dominante/s e feminilidade/s subalterna/s.

Por ser um modelo cultural ideal, inatingível na prática de forma consistente e inalterada, a "masculinidade" exerce, sobre homens e mulheres, "um efeito controlador" (ALMEIDA, 1996, p. 163). Ademais, conforme aponta Kimmel (1998), considerando que tanto a masculinidade hegemônica quanto a feminilidade ideal produzidas pela sociedade patriarcal são imperceptíveis aos atores sociais, vêm ocorrendo, contemporaneamente, algumas transformações nas experiências e visões de mundo consideradas específicas de homens e mulheres.

No caso específico das narrativas em análise nesta pesquisa, observamos, por exemplo, que papéis considerados exclusivamente masculinos - como "provedor" e "chefe de família" - estão sendo relativizados por outros atributos como "mulher forte", "corajosa", "empreendedora". São exatamente essas representações que podemos observar em (1) e $(2)^{5}$ :

\begin{tabular}{|c|c|c|}
\hline $\begin{array}{l}001 \\
002\end{array}$ & Fábio & $\begin{array}{l}\text { Bom Laís é:: eu quero que você conta a tua história } \uparrow \text { QUEM É } \\
\text { A LAÍS quem é a Laís como foi tua vida? me conta }\end{array}$ \\
\hline $\begin{array}{l}003 \\
004 \\
005\end{array}$ & Laís & $\begin{array}{l}\text { a:: a minha vida não foi nada fácil né? eu tenho três filhos } \\
\text { sempre batalhei sempre sempre criei os três SOZINHA né? } \\
\text { pago aluguel energia }\end{array}$ \\
\hline 006 & Fábio & e a infância? \\
\hline $\begin{array}{l}007 \\
008 \\
003\end{array}$ & Laís & $\begin{array}{l}\text { também não foi nada fácil eu vim de uma infância muito pobre } \\
\text { eu morava no Paraná Cascavel já morei na favela já catei papelão }\end{array}$ \\
\hline
\end{tabular}

5 Todos os eventos comunicativos foram transcritos de acordo com o modelo de transcrição elaborado por Loder (2008). 


\begin{tabular}{|c|c|c|}
\hline 009 & Fábio & você morou na favela onde? \\
\hline 010 & Laís & em Cascavel Paraná \\
\hline 011 & Fábio & $<$ nossa $>$ \\
\hline $\begin{array}{l}012 \\
013 \\
014 \\
015 \\
016 \\
017\end{array}$ & Laís & $\begin{array}{l}\text { já morei meu filho } \uparrow H O J E \text { AQUI EU SOU RICA eu me sinto } \\
\text { uma MILIONÁRIA hoje você sabia? eu me sinto uma } \\
\text { milionária hoje eu vejo em Rio Preto aquele povo lá catando } \\
\text { latinha aqueles carrinhos de papelão eu juro por Deus eu } \\
\text { cheguei chorar de ver aquilo porque eu lembro de } \downarrow \text { tudo isso da minha } \\
\text { infância }\end{array}$ \\
\hline 018 & Fábio & na tua infância [você fazia isso ] \\
\hline 019 & Laís & [na minha infância] \\
\hline 020 & Fábio & e dava pra você ir pra escola ou não? \\
\hline $\begin{array}{l}021 \\
022 \\
023\end{array}$ & Laís & $\begin{array}{l}\text { †IA E AINDA IA eu catava latinha papelão é:: lá no Paraná } \\
\text { existe osso né? aqui não existe mais mas lá a gente vende osso } \\
\text { né? vixe filho eu vim de uma infância bem triste }\end{array}$ \\
\hline
\end{tabular}

(2)

\begin{tabular}{|c|c|c|}
\hline 001 & Laís & ó:: eu vim do nada \\
\hline 002 & Fábio & humm \\
\hline 003 & Laís & com três filhos eu tô construindo minha casa própria \\
\hline 004 & Fábio & SOZINHA \\
\hline 005 & Laís & SOZINHA graças a Deus eu trabalho lá no haras \\
\hline 006 & Fábio & ãmm \\
\hline $\begin{array}{l}007 \\
008 \\
009 \\
010 \\
011 \\
012 \\
013\end{array}$ & Laís & 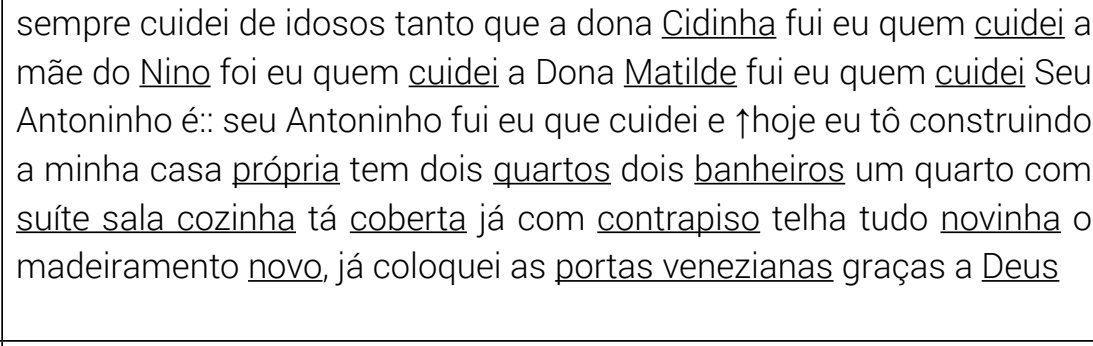 \\
\hline 014 & Fábio & $\uparrow S E M$ APOIO DE NINGUÉM? \\
\hline $\begin{array}{l}015 \\
016 \\
017 \\
018\end{array}$ & Laís & $\begin{array}{l}\text { sem apoio DE NINGUÉM graças ao meu bom Deus por isso que eu te } \\
\text { falo eu me sinto hoje não rica mas MAIS DO QUE RICA eu me sinto } \\
\text { MILIONÁRIA do que quando eu vim lá da minha infância da favela e hoje } \\
\text { eu consegui tudo graças a Deus }\end{array}$ \\
\hline 019 & Fábio & tem que saber que você venceu \\
\hline 020 & Laís & venci e uma grande vitória \\
\hline
\end{tabular}




\begin{tabular}{|c|c|c|}
\hline 021 & Fábio & isso é certo pra você? você consegue enxergar isso? \\
\hline 022 & Laís & eu consigo enxergar isso \\
\hline 023 & Fábio & que você é uma mulher que [conseguiu ] \\
\hline $\begin{array}{l}024 \\
025\end{array}$ & Laís & $\begin{array}{l}\quad[\uparrow E U \text { ME ACHO EU MESMA ME ACHO >não } \\
\text { posso me sentir convencida< mas eu me acho guerreira guerreira } \\
(\text { (risos) })\end{array}$ \\
\hline 026 & Fábio & sem dúvidas né? ((risos)) \\
\hline 027 & Laís & eu me acho graças a Deus \\
\hline
\end{tabular}

No que diz respeito aos excertos (1) e (2), podemos afirmar que, no plano da prática discursiva, propriamente no que tange à construção dos significados acionais e identificacionais, as avaliações da narrativa em curso estão baseadas em apreciações de composição (Cf. MARTIN; WHITE, 2005) (rica, milionária), que associadas a julgamentos positivos de estima social, assentados tanto no que Martin e White (2005) denominam "tenacidade" - o grau de resolução ou perseverança - quanto "capacidade" - o grau de competência (eu consegui tudo graças a Deus, eu venci é uma grande vitória, eu me acho eu mesma me acho - não posso me sentir convencida - mas eu me acho guerreira) indicam que a entrevistada reivindica, para si, subliminarmente no plano da construção do significado "identificacional", uma identidade associada não à feminilidade ideal, mas à masculinidade hegemônica: o self-made-man (cf. BRUNELLI, 2016). Trata-se não só de uma mulher que se apresenta como "provedora" e "chefe de família", mas de uma pessoa de sucesso que conquistou suas vitórias acreditando no seu próprio potencial. Essa imagem contrasta com outra, associada ao perfil contrário: "o trabalhador frustrado, lamentador, que culpa o mundo e as coisas que estão ao seu redor pelo próprio fracasso" (BRUNELLI, 2016, p. 35).

Na verdade, nos exemplos em questão, observa-se a construção, no plano da prática social, de um discurso meritocrático, demarcado ainda pela neutralização dos estigmas de classe, cor e gênero. Por meio desse discurso, a informante busca se diferenciar das demais mulheres negras e pobres que residem em seu bairro periférico e rejeitar os estereótipos associados a esse segmento. Nesse sentido, o gerenciamento desses estereótipos colabora para a manutenção do status quo, auxiliando a promover a crença de um mundo justo: "conquista e riqueza são para quem se esforça, [...] acredita no próprio potencial e arregaça as mangas. Já o fracasso, as frustrações, [...] não são consequências de um mundo desigual, que não oferece oportunidades iguais a todos, mas fruto da falta de mérito, da falta de confiança [...]" (BRUNELLI, 2016, p. 35).

De forma análoga, a meritocracia, tal como se anuncia 
[...] quer fazer-nos crer que o êxito depende do esforço e os talentos individuais, o que significa que a responsabilidade reside inteiramente no indivíduo e que a autoridade deveria outorgar às pessoas toda a liberdade possível para alcançar esta meta. [...] Somos os únicos culpáveis de nossos fracassos, um mal que temos que responder ante todos os demais e ante nossa jurisdição íntima [...]. O "mérito" agora é nossa condição, nosso destino. Junto com o mercado da espiritualidade e da fé, a "meritocracia" constitui não somente a maior indústria da época, senão é também, e com maior exatidão, o novo imperativo moral: devemos a nós mesmos o "mérito" tanto como nos o devem os demais. (FERNANDEZ; FERNANDEZ, 2015, p. 8).

Características bastante semelhantes aos exemplos anteriores permeiam as narrativas em questão, indicando uma espécie de hegemonia no material analisado. Observe, a esse respeito, os exemplos (3) e (4):

(3)

\begin{tabular}{|c|c|c|}
\hline $\begin{array}{l}001 \\
002 \\
003\end{array}$ & Michele & $\begin{array}{l}\text { AHH hoje hoje nossa totalmente diferente né? hoje eu não não vejo nada } \\
\text { disso } \text { ¡nem uma pessoa julgou cada um se você lutar por aquilo aquele } \\
\text { objetivo que você tem você [consegue ] }\end{array}$ \\
\hline 005 & Fábio & [certo certo] \\
\hline $\begin{array}{l}006 \\
007 \\
008 \\
009 \\
011 \\
012 \\
013 \\
014 \\
015\end{array}$ & Michele & $\begin{array}{l}\text { esse curso mesmo que eu comecei a fazer eu achava assim eu falei- } \\
\text { tava falando até pro meu esposo "nossa eu tô me sentindo assim que eu } \\
\text { achava que assim não era capaz pra abrir a mente pra mais coisas tipo } \\
\text { administração" e eu tava gostando tanto que eu tava conseguindo fazer e } \\
\text { algo que:: eu tinha parado de estudar [e:: ] eu me senti muito feliz } \uparrow \text { senti } \\
\text { que eu CONSIGO senti CAPAZ de novo que eu sei que eu posso achava } \\
\text { que eu não podia você achava que aquele lá é inteligente mas você não } \\
\text { é e eu pude ver que não é é a GENTE querer se esforçar por aquilo que } \\
\text { você quer }\end{array}$ \\
\hline 016 & Fábio & ótimo \\
\hline 017 & Michele & aí é outra visão \\
\hline
\end{tabular}


(4)

\begin{tabular}{|c|c|c|}
\hline $\begin{array}{l}001 \\
002 \\
003 \\
004 \\
005 \\
006 \\
007 \\
008\end{array}$ & Fernanda & $\begin{array}{l}\text { então desde a minha infância né? não foi uma infância fácil porque } \\
\text { comecei a trabalhar muito cedo é... meu pai alcóolatra muita briga } \\
\text { dentro de casa muita briga aí houve a separação aí aos quatorze anos } \\
\text { fui morar com meu pai aí logo comecei a ter amizade que bebia saía } \\
\text { pra balada aí fiquei grávida com quinze anos não tive infância não } \\
\text { tive é:: juvenTUde nada disso. E continuei trabalhando né? achei que } \\
\text { ia ter uma vida melhor depois do casamento mas não foi nada fácil } \\
\text { porque eu tinha um marido que me batia [inaudível] }\end{array}$ \\
\hline 009 & Fábio & [você era] [agredida] \\
\hline $\begin{array}{l}010 \\
011 \\
012 \\
013 \\
014 \\
015 \\
016\end{array}$ & Fernanda & $\begin{array}{l}\text { [uhumm ] muita agressão } \\
\text { eu ainda de menor achava que dependia dele pra tudo né? mas aí com o } \\
\text { passar do tempo eu fui aprendendo a viVEr fui criando coRAgem decidi } \\
\text { denunciÁ-lo foi pre::so aí (.) e com o passar do tempo fui morar sozinha } \\
\text { com meus filhos trabalhei sempre até hoje trabalho não moro com meu } \\
\text { espo::so que é pai dos meus filhos e graças a Deus eu venci na VIda }\end{array}$ \\
\hline 017 & Fábio & Uummm \\
\hline $\begin{array}{l}018 \\
019 \\
020 \\
021 \\
022 \\
023\end{array}$ & Fernanda & $\begin{array}{l}\text { E ainda continuo lutando faço faxina sou faxineira com orgulho e agora } \\
\text { consegui uma profissão de manicure faço minhas unhas de final de } \\
\text { semana feria::.dos e:: graças a deus meus filhos estudam têm uma boa } \\
\text { educação que eu conseGUI né? passar pra eles uma boa educação e eu } \\
\text { sempre falo que eu não quero tratar meus filhos do jeito que eu fui criada }\end{array}$ \\
\hline 024 & Fábio & e como você foi criada? \\
\hline $\begin{array}{l}025 \\
026 \\
027 \\
028 \\
029\end{array}$ & Fernanda & $\begin{array}{l}\text { era muita violência dentro de casa. minha mãe sempre me bati::a não } \\
\text { tinha diálogo com minha mã::e não tive uma mãe amiga por isso que } \\
\text { eu engravidei ce::.do então achava que era mais fácil ir morar com um } \\
\text { rapaz mesmo sem gostar dele do que ficar dentro da casa da minha } \\
\text { mãe aguentando humilhação }\end{array}$ \\
\hline 030 & Fábio & E assim que você -você fugiu? \\
\hline $\begin{array}{l}031 \\
032 \\
033 \\
034 \\
035 \\
036 \\
037\end{array}$ & Fernanda & 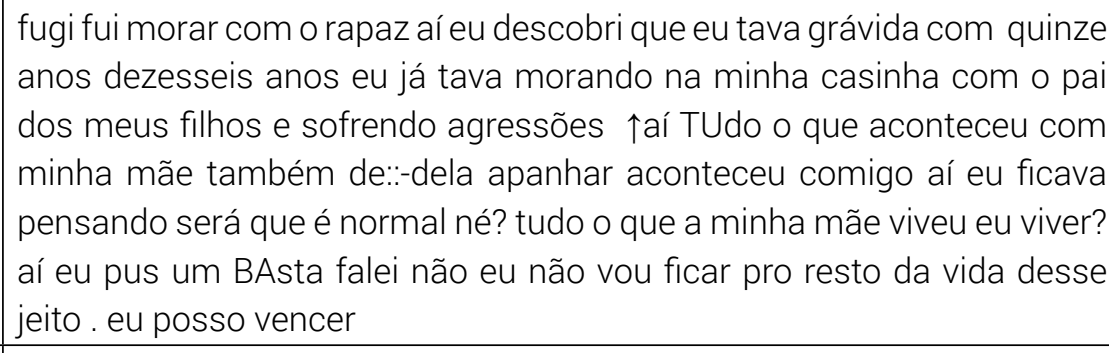 \\
\hline 038 & Fábio & e você? \\
\hline 039 & Fernanda & venci \\
\hline
\end{tabular}


Cumpre destacar que os recursos avaliativos, inscritos no plano da construção dos significados identificacionais e acionais - e, portanto, associados à metafunção interpessoal de Halliday (1985) - instanciam, no plano da prática social, ainda mais aspectos morais e ideológicos. Trata-se de julgamentos de estima social ligados à capacidade (senti que eu consigo senti capaz de novo, que eu sei que eu posso; com o passar do tempo eu fui aprendendo a viver fui criando coragem decidi denunciá-lo; uma boa educação que eu consegui né? passar pra eles uma boa educação) e à tenacidade (graças a Deus eu venci na Vida) das entrevistadas, por meio dos quais se torna possível observar que elas reivindicam, para si, mais uma vez, a identidade de mulheres "guerreiras", que "venceram" por seu próprio mérito.

Se essas identidades atravessam, no mais das vezes, as questões de gênero, ao se associarem à masculinidade hegemônica ("provedoras" e "chefe-de-família"), devemos destacar que a ideologia meritocrática perpassa, inevitavelmente, outro atravessamento sob análise neste trabalho: a "classe social".

Considerando-se a associação estabelecida por Linde (1997) entre avaliação e dimensão moral da narrativa, os trechos em destaque acenam para o que Sarti (2011) denomina "moral dos pobres". Nesse universo, de acordo com a autora, o esforço do trabalho emerge como um valor moral, através do qual o pobre dá o que tem: "a disposição de trabalhar" (SARTI, 2011, p. 90).

É nesse contexto que podemos entender as avaliações presentes em diversos trechos das narrativas sob análise: sempre batalhei sempre sempre criei os três sozinha né? Pago aluguel energia (em ((1)); eu vim do nada, com três filhos eu tô construindo minha casa própria; sozinha graças a Deus eu trabalho lá no haras; sempre cuidei de idosos; sem apoio de ninguém (em (2)); e eu pude ver que não é é a gente querer se esforçar por aquilo que você quer (em (3)); comecei a trabalhar muito cedo; e continuei trabalhando, né? trabalhei sempre até hoje trabalho não moro com meu esposo que é pai dos meus filhos; e ainda continuo lutando faço faxina sou faxineira com orgulho e agora consegui uma profissão de manicure (em (4)).

De acordo com Sarti (2011), o trabalho para sustentar os filhos redime a mulher "mãe solteira", que se torna provedora. Subordinado à maternidade, o trabalho torna-se, então, "um aspecto capaz de conferir à mulher a mesma autonomia moral que é reconhecida no homem/trabalhador/provedor" (p. 76). Na ausência da figura masculina, a mulher tem a "disposição para aceitar qualquer batente [...], porque o significado de seu trabalho remunerado é mediado pelo seu papel de mãe e dona-de-casa, para suprir o que sabe que está faltando" (p. 102).

De modo simultâneo às novas representações de gênero destacadas nesta pesquisa, concorrem modelos bastante próximos a uma feminilidade ideal - mulher como boa mãe, boa dona-de casa. Observe: 
(5)

\begin{tabular}{|c|c|c|}
\hline 001 & Fábio & se você fosse falar assim quem é a Luzia? \\
\hline 002 & Luzia & quem é a Luzia agora? uma mãezona \\
\hline 003 & Fábio & umm \\
\hline $\begin{array}{l}004 \\
005 \\
006 \\
007 \\
008 \\
009 \\
010\end{array}$ & Luzia & $\begin{array}{l}\text { uma esposa que ama o marido que é amada . entendeu? uma esposa } \\
\text { que tem prazer de cuidar da sua casa de fazer:: colocar uma mesa } \\
\text { bonita pra esperar o seu esposo fazer as coisas que ele gosta as coisas } \\
\text { que a minha filha gosta eu tenho prazer em ficar na minha casa eu amo } \\
\text { este bairro }\end{array}$ \\
\hline
\end{tabular}

Vale destacar que, em (5), ao invés da forte recorrência dos julgamentos de estima social - muito presentes nos exemplos anteriores, em que as informantes reivindicavam para si o self-made-man - o significado identificacional é construído, sobretudo, no plano da prática textual, a partir da categoria do "afeto", propriamente de "satisfação" (Cf. MARTIN; WHITE, 2005), bastante próximo, portanto, dos valores que se articulam em torno da imagem de mulher ideal e "boa mãe" (Uma esposa que ama o marido que é amada entendeu? Uma esposa que tem prazer de cuidar da sua casa. Fazer as coisas que ele gosta as coisas que a minha filha gosta. Eu tenho prazer em ficar na minha casa eu amo este bairro), associados a uma apreciação de qualidade (uma mesa bonita pra esperar o seu esposo).

Na verdade, a família se apresenta como a referência simbólica fundamental para os pobres, a partir da qual atribuem significado ao mundo social, dentro e fora de casa. Nesse contexto, os projetos de melhorar de vida são formulados enquanto projetos familiares. De uma maneira bastante próxima à feminilidade ideal - mulher como boa mãe, boa dona-de-casa - e, portanto, associada à questão de gênero - o casamento se torna o projeto inicial de construção da família, a partir do qual são formulados os projetos de melhorar de vida, ancorados numa complementaridade entre homem e mulher ${ }^{6}$.

\section{Conclusão}

Partindo de pontos de convergência observados a priori entre a Análise da Narrativa, situada no contexto da proposta Socioconstrucionista para a Linguística Aplicada brasileira contemporânea, e a ACD, fundamentalmente o compromisso social e político que ecoa em ambas as vertentes, interessadas na desconstrução de práticas sociais

6 Não estamos, com isso, querendo afirmar que os aspectos dessa moral não possam permear outras classes sociais. Apenas sustentamos, em consonância com Sarti (2011), que tais aspectos são fundamentais para as classes populares. 
injustas e na transformação dessas práticas, propusemos estabelecer e explorar, neste artigo, pontos de contato teóricos e metodológicos. Para tal, assumimos como pressuposto teórico o Modelo de Análise Tridimensional proposto por Fairclough (1997, 2001 , 2003) à ACD e algumas propostas ditas "não canônicas" de narrativa, em especial aquela apresentada por Linde $(1993,1997)$.

Nesse contexto, a avaliação tornou-se, indubitavelmente, o principal viés a alinhavar ambas as vertentes. Se, para a Análise da Narrativa, é durante a avaliação que o enunciador encontra espaço para comentar aspectos do que foi narrado, deixando entrever suas crenças, valores, afiliações, posicionamentos na hierarquia social, qualificações e, assim, construir sua identidade, em uma perspectiva que reforça a associação entre avaliação e dimensão moral da narrativa (cf. BASTOS, 2005; LINDE, 1997), para o Modelo Tridimensional é também através da análise dos recursos avaliativos, inscritos no âmbito da constituição dos significados identificacionais e acionais, que se podem observar as maneiras pelas quais os enunciadores tanto atribuem determinadas identidades sociais a si mesmo e aos atores designados em seu texto quanto expressam seus posicionamentos e julgamentos, associados (ou não) a determinadas ideologias e consensos hegemônicos estabelecidos socialmente.

Com a análise dos dados foi possível constatar o forte e indiscutível imbricamento entre os atravessamentos "gênero" e "classe social", ratificando a necessidade teórica de se compreender o sujeito social sempre interseccionado pelos atravessamentos mencionados, como traços performativos imbricados, por meio dos quais os mesmos constroem suas identidades sociais e atribuem sentidos ao mundo ao seu redor.

Durante as avaliações das narrativas analisadas, foi possível observar como as identidades localmente instituídas relacionam-se com discursos especializados ou de senso comum que circulam na sociedade, bem como as maneiras pelas quais as informantes buscaram se dissociar de determinados estereótipos sociais, a partir de determinadas recorrências e resistências. Foi nesse contexto que apontamos um forte alinhamento com consensos hegemônicos que circunscrevem a sociedade brasileira em geral e as classes populares em particular, em especial no que diz respeito à concepção da masculinidade enquanto modelo ideal e hegemônico, à atribuição de um valor moral ao esforço do trabalho, dentre outros.

No caso específico do atravessamento "gênero", foi possível notar transformações nas experiências e visões de mundo consideradas específicas de homens e mulheres, concorrendo com modelos mais tradicionais. Nesse sentido, papéis considerados exclusivamente masculinos - como "provedor" e "chefe de família" - estão sendo relativizados e reivindicados pelas informantes mulheres, mediante atributos que constroem suas identidades enquanto "mulheres fortes", "corajosas", "empreendedoras", mais próximos à masculinidade hegemônica (o self-made-man) e mais distantes da feminilidade ideal. 
Se essas identidades atravessam as questões de gênero, ao se associarem à masculinidade hegemônica ("provedoras" e "chefe de família"), observamos nesses excertos uma intersecção com o atravessamento "classe social", através da consolidação de uma moral característica das classes populares, caracterizada por conferir ao trabalho um valor moral, profundamente associada a uma ideologia meritocrática em uníssono, a qual tem se apresentando, possivelmente, como um novo consenso hegemônico. Demarcada pela neutralização dos estigmas de classe e gênero, a ideologia meritocrática tornou-se uma ferramenta para as informantes se diferenciarem das demais mulheres negras e pobres que residem em seu bairro periférico, e assim rejeitarem a pertença ao grupo estereotipado.

\section{REFERÊNCIAS}

ALMEIDA, M. V. Senhores de si: uma interpretação antropológica da masculinidade. Lisboa: Fim do Século, 1995.

BASTOS, L. C. Contando estórias em contextos espontâneos e institucionais - uma introdução ao estudo da narrativa. Calidoscópio, v. 3, n. 2, p. 74-87, 2005.

BASTOS, L. C.; BIAR, L. A. Análise de narrativa e práticas de entendimento da vida social. DELTA, v. 31, n. esp., p. 97-126, 2015.

BASTOS, L. C.; SANTOS, W. S. Introdução: Entrevista, narrativa e pesquisa. In: BASTOS, L. C.; SANTOS, W. S. (org.). A entrevista na pesquisa qualitativa. Rio de Janeiro: Quartet/ FAPERJ, 2013. p. 9-18.

BIAR, L. A. Demarcando território? Situando a linguística aplicada "indisciplinar". Linguagem em (Re)vista, ano 6, n. 10, p. 127-144, 2009.

BRUNELLI, A. F. Estereótipos e Desigualdades Sociais: contribuições da Psicologia Social à Análise do Discurso. Cadernos de Estudos Linguísticos (UNICAMP), v. 58, n. 1, p. 25-43, 2016.

DENZIN, N. K.; LINCOLN, Y. S. Introdução: a disciplina e a prática da pesquisa qualitativa. In: DENZIN, N. K.; LINCOLN, Y. S. (org.). O planejamento da pesquisa qualitativa: teorias e abordagens. 2. ed. Porto Alegre: Artmed, 2006. p. 15-41.

FAIRCLOUGH, N. Discourse and social change. Cambridge: Polity Press, 1992. 
FAIRCLOUGH, N. Discurso e mudança social. Tradução Izabel Magalhães. Brasília: Editora da Universidade de Brasília, 2001.

FAIRCLOUGH, N. Analysing Discourse: textual analysis for social research. Londres: Routledge, 2003.

FERNANDEZ, A.; FERNANDEZ, A. Meritocracia e desigualdade. Derecho y cambio social, n. 42, p. 1-15, 2015.

FREITAS, M. A. A masculinidade hegemônica na cultura brasileira. Revista de Psicologia, v. 20, n. 1, p. 28-41, 2002.

HALLIDAY, M. A. K. Introduction to functional grammar. Londres: Edward Arnold, 1985.

KIMMEL, M. A produção simultânea da masculinidade hegemônica e subalterna. Horizontes Antropológicos, v. 9, n. 4, p. 103-118, 1998.

LABOV, W. Language in the inner city: studies in the Black English Vernacular. Philadelphia: University of Pennsylvania Press, 1972.

LABOV, W.; WALETZKY, J. Narrative Analysis: oral versions of personal experience. In: HELM, J. Essays on the verbal and visual arts. Seattle: University of Washington Press, 1967.

LINDE, C. Life stories. The creation of the coherence. Nova York: Oxford University Press, 1993.

LINDE, C. Evaluation as linguistic structure and social practice. In: GUNNARSSON, B. L.; LINELL, P.; NORDBERG, B. (ed.). The construction of professional discourse. Londres: Longman, 1997.

LODER, L. L. O modelo Jefferson de transcrição: convenções e debates. In: LODER, L. L.; JUNG, N. M. (org.). Fala-em-interação social: introdução à Análise da Conversa Etnometodológica. Campinas: Mercado de Letras, 2008. p. 127-160.

MAGALHÃES, I. Discurso, Ética e Identidades de Gênero. In: MAGALHÃES, C.; GRIGOLETTO, R. (org.). Práticas identitárias: língua e discurso. São Carlos: Claraluz, 2006. p. 71-96. 
MARTIN, J. R.; WHITE, P. R. R. The language of evaluation: appraisal in English. Nova York/Hampshire: Palgrave Macmillan, 2005.

MISHLER, E. G. The analysis of interview-narratives. In: SARBIN, T. R. (org.). Narrative Psychology. The storied nature of human conduct. New York: Praeger, 1986.

MISHLER, E. G. Narrativa e identidade: a mão dupla do tempo. In: MOITA LOPES, L. P.; BASTOS, L. C. (org.). Identidades: recortes multi e interdisciplinares. Campinas: Mercado das Letras, 2002. p. 97-119.

MOITA LOPES, L. P. Linguística Aplicada e vida contemporânea: problematização dos construtos que têm orientado a pesquisa. In: MOITA LOPES, L. P. Por uma linguística aplicada indisciplinar. São Paulo: Parábola, 2006.

MOITA LOPES, L. P. Identidades fragmentadas. Campinas: Mercado de Letras, 2002.

MOITA LOPES, L. P. Práticas narrativas como espaço de construção das identidades sociais: uma abordagem socioconstrucionista. In: RIBEIRO, B. T.; LIMA, C. C.; DANTAS, M. T. L. (org.). Narrativa, identidade e clínica. Rio de Janeiro: Ipub, 2001.

RESENDE, V. M. Análise de Discurso Crítica, Etnografia e representações do "bom" professor. In: XVII CONGRESSO INTERNACIONAL DA ASSOCIAÇÃO DE LINGUÍSTICA E FILOLOGIA DA AMÉRICA LATINA, 2014, João Pessoa. XVII Congreso Internacional Asociasión de Lingüística y Filologia de América Latina. Anais. João Pessoa, 2014. Disponível em: http://www.mundoalfal.org/CDAnaisXVII/trabalhos/R0521-1.pdf. Acesso em: 31 ago. 2019.

RIESSMAN, C. K. Narrative Methods for the Human Sciences. Londres: Sage, 2008.

SARTI, C. A. A família como espelho: um estudo sobre a moral dos pobres. São Paulo: Cortez, 2011.

VAN DIJK, T. A. Discurso, poder y cognición social. Cuadernos, n. 2, 1994. Disponível em: http://www.discursos.org/oldarticles/Discurso,\%20poder\%20y\%20cognici\%F3n\%20 social.pdf. Acesso em: 6 jun. 2007.

WODAK, R. Do que trata a ACD: um resumo de sua história, conceitos importantes e seus desenvolvimentos. Linguagem em (Dis)curso, Tubarão, v. 4, n. esp., p. 223-243, 2004. 